\title{
Chatting online - is this good for you?
}

\author{
Ana Maria Tudor ${ }^{1,2^{*}}$, Mariana Mărdărescu', Ruxandra Neagu-Drăghicenoiu', Rodica Ungurianu' ${ }^{1}$ Adrian Abagiu', \\ Carina Matei ${ }^{1}$, Ioana-Catrinel Cercel ${ }^{1}$, Cristian Anghelina' ${ }^{1}$, Mioara Predescu ${ }^{3}$ \\ From The 9th Edition of the Scientific Days of the National Institute for Infectious Diseases Prof Dr Matei Bals \\ Bucharest, Romania. 23-25 October 2013
}

\section{Background}

We aim to describe physicians' experience as a part of web conferences project involving health care practitioners, governmental and nongovernmental organizations targeting health education among people living with HIV (PLHIV).

\section{Methods}

We analyze different aspects of a project developed by nongovernmental organizations for people affected by HIV, namely the Romanian Anti-AIDS Association (ARAS), the National Union of Organizations of People Affected by HIV/AIDS (UNOPA) along with the Romanian HIV/AIDS Center and the National Institute for Infectious Diseases "Prof. Dr. Matei Balş". Medical, psychological and social support was given by Matei Balş personnel. The conferences offered direct connection between AIDS care specialists and patients. The IT logistics was provided by Data Center Solutions.

\section{Results}

Two series of conferences consisting of six sessions provided information for more than 1000 visitors. In each session there were 2 health care practitioners, in total 5 physicians, 2 psychologists and one social worker. The main themes proposed by AIDS experts were: HIV transmission, treatment, adherence, parenting for HIV infected children, emotional problems faced by HIV patients, social and psychological support, IV drug users, antiretrovirals' adverse reactions, pregnancy and HIV, hepatitis C coinfection. Patients' focus was on metabolic problems associated with antiretroviral treatment, legal rights for HIV infected persons, HIV cure, antiretroviral supplies, protection for partners and future children.

\footnotetext{
* Correspondence: tudoranamaria@yahoo.com

${ }^{1}$ National Institute for Infectious Diseases "Prof. Dr. Matei Balş", Bucharest, Romania

Full list of author information is available at the end of the article
}

\section{Conclusion}

Health care practitioners had the opportunity to identify the problems faced by patients, their concerns. Patients took advantage from asking questions under protection of undisclosed identity. The feedback from both parties, patients and AIDS experts was positive. All the partners involved benefit from this project.

\section{Authors' details}

${ }^{1}$ National Institute for Infectious Diseases "Prof. Dr. Matei Balş", Bucharest, Romania. ${ }^{2}$ Carol Davila University of Medicine and Pharmacy, Bucharest, Romania. ${ }^{3}$ Romanian HIV/AIDS Center, Bucharest, Romania.

Published: 16 December 2013

doi:10.1186/1471-2334-13-S1-O4

Cite this article as: Tudor et al:: Chatting online - is this good for you? BMC Infectious Diseases 2013 13(Suppl 1):O4.
Submit your next manuscript to BioMed Central and take full advantage of:

- Convenient online submission

- Thorough peer review

- No space constraints or color figure charges

- Immediate publication on acceptance

- Inclusion in PubMed, CAS, Scopus and Google Scholar

- Research which is freely available for redistribution

Submit your manuscript at www.biomedcentral.com/submit
() Bïomed Central
C Biomed Central

(c) 2013 Tudor et al; licensee BioMed Central Ltd. This is an Open Access article distributed under the terms of the Creative Commons Attribution License (http://creativecommons.org/licenses/by/2.0), which permits unrestricted use, distribution, and reproduction in any medium, provided the original work is properly cited. 